TSEISMOLOGY

\title{
Slow slip promoted by fault heterogeneity
}

Destructive large magnitude earthquakes at subduction zones are associated with rapid slip along the plate interface. However, at many subduction zones the majority of tectonic plate motion can occur during long-duration and non-destructive slow slip events, which often go undetected owing to their weak seismic tremor. The mechanisms of slow slip events and how they are related to large magnitude earthquakes remain debated, partly due to inadequate direct observations of actively slipping megathrust faults.

Philip Barnes, from the National Institute of Water and Atmospheric Research, New Zealand, and colleagues analysed drill cores recovered from the incoming plate at the Hikurangi margin, offshore New Zealand, providing important constraints on the properties of fault zone rocks entering the slow slip source region ( $2-15 \mathrm{~km}$ depth). The results reveal that the incoming material, representing the slow slip

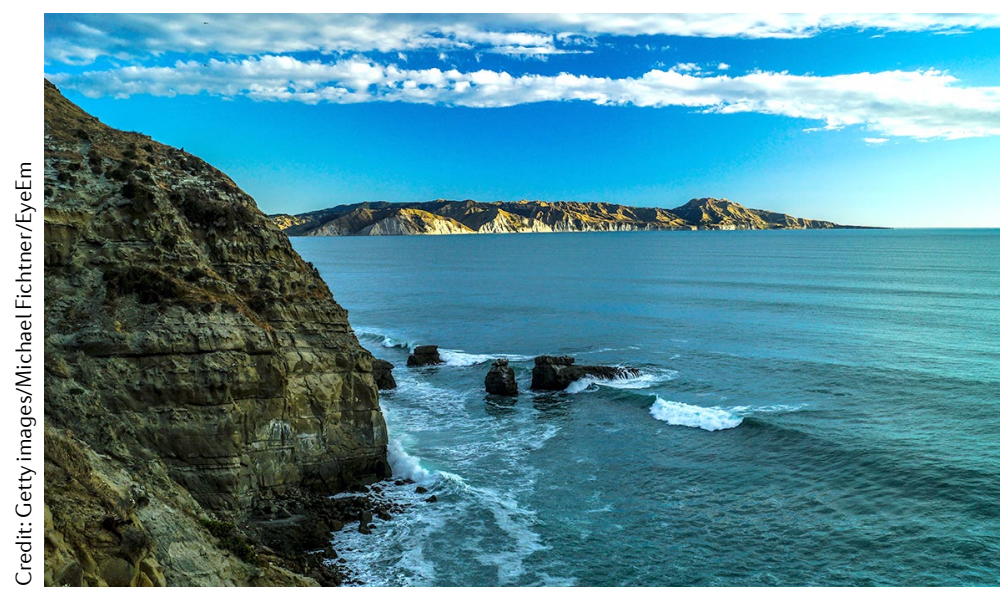

megathrust, is compositionally and rheologically heterogeneous over multiple scales, as both altered and unaltered volcanic rocks are intermingled with marine sediments. In addition, seismic reflection images, when tied to the drilling results, reveal a highly uneven fault geometry, due to the subduction of a rough oceanic plate disrupted by normal faults and volcanic seamounts. Over weeks to months, broad regions of slow slip can result from propagation and linkage of smaller events that nucleate from within the numerous heterogeneities at the centimetre to kilometre scale.

The unusually shallow (as low as $\sim 2 \mathrm{~km}$ ) slow slip source region at the Hikurangi margin provides a unique opportunity to constrain prior models of slow slip earthquakes. Indeed, the results from Hikurangi confirm conceptual models that compositional, geometrical and rheological heterogeneity at the plate interface could result in the co-existence of both seismic and aseismic slip. However, true direct observations and sampling of the active slow slip source region itself will require targeting by future deep ocean drilling projects.

Erin Scott

Nature Communications

ORIGINAL ARTICLE Barnes, P. M. et al. Slow slip source characterized by lithological and geometric heterogeneity. Sci. Adv. 6, eaay3314 (2020) 